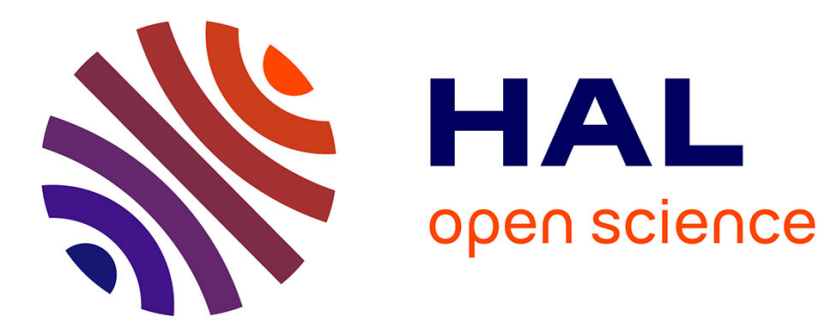

\title{
Wavelet transform: A tool for the interpretation of upper mantle converted phases at high frequency
}

\author{
Julie Castillo, Antoine Mocquet, Ginette Saracco
}

\section{To cite this version:}

Julie Castillo, Antoine Mocquet, Ginette Saracco. Wavelet transform: A tool for the interpretation of upper mantle converted phases at high frequency. Geophysical Research Letters, 2001, 28 (22), pp.4327-4330. 10.1029/2001GL013214 . hal-01767215

\section{HAL Id: hal-01767215 \\ https://hal.science/hal-01767215}

Submitted on 16 Apr 2018

HAL is a multi-disciplinary open access archive for the deposit and dissemination of scientific research documents, whether they are published or not. The documents may come from teaching and research institutions in France or abroad, or from public or private research centers.
L'archive ouverte pluridisciplinaire HAL, est destinée au dépôt et à la diffusion de documents scientifiques de niveau recherche, publiés ou non, émanant des établissements d'enseignement et de recherche français ou étrangers, des laboratoires publics ou privés. 


\title{
Wavelet transform : A tool for the interpretation of upper mantle converted phases at high frequency
}

\author{
Julie Castillo, Antoine Mocquet, \\ Laboratoire de Planétologie et Géodynamique, Nantes University, France.
}

Ginette Saracco ${ }^{1}$

Laboratoire de Géosciences, Rennes University, France.

\begin{abstract}
P}$ to $\mathrm{S}$ converted receiver functions recorded at VBB FDSN California stations are studied in the frequency range of 0.1 to $1 \mathrm{~Hz}$. Microseismic noise is maximum in this frequency range, but signal processing by the wavelet transform enables us: (1) to enhance seismic phases associated with seismic velocity gradients and discontinuities at the base of the upper mantle, (2) to extract accurate arrival times, and (3) to obtain an accurate insight into the frequency content. In the case of California, one seismic discontinuity and two zones of high gradients in the depth range of 625 to $720 \mathrm{~km}$ are recurrently observed for two different data sets.
\end{abstract}

\section{Introduction}

Many studies have focused on the interface between the upper and the lower mantle of the convective Earth. The diversity of seismic phases and frequency ranges used for the interpretation has lead to the construction of different models. The most commonly used model consists of a less than 5-km thick discontinuity (e.g. Paulssen [1985]) which is situated at a depth of $660 \mathrm{~km}$ in spherically symmetric Earth models, hereafter abbreviated as SSEM (e.g. ak135, [Kennett et al., 1995]). Mineral physics indicates that the depth at which this seismic discontinuity occurs varies inversely with respect to lateral variations of temperature, due to the endothermic transformation of ringwoodite ( $\gamma$-phase) into perovskite $(\mathrm{Pv})$ and magnesiowustite $(\mathrm{Mw})$ (e.g. Ito and Takahashi [1989]). Studies also predict the presence of high velocity gradients which should be associated with the transformation of non-olivine minerals (i.e. garnet and ilmenite) [Vacher et al., 1998]. These results support the opinion that the seismic velocity and density jump introduced in SSEM at a depth of $660 \mathrm{~km}$ should only be regarded as the simplest expression of a more complicated pattern of multiple high gradients and discontinuities. Although the impedance contrast associated with the transformation of non-olivine components is predicted to be 6 times smaller than the one associated with the transformation of olivine phases, observations by Niu and Kawakatsu [1996] under Japan and China, and Simmons and Gurrola [2000] under California, suggest that the former transformations might be detected

\footnotetext{
${ }^{1}$ Now at Laboratoire Cerege, Aix-Marseille, France.
}

Copyright 2001 by the American Geophysical Union.

Paper number 2001GL013214.

0094-8276/01/2001GL013214\$05.00 by seismological means. Since the amplitude of a converted phase depends on the ratio between the width of the interface and the wavelength, the frequency content of dispersed waveforms provides information on the smoothness of seismic discontinuities. High seismic gradients related to non-olivine transformations are 10 to $50 \mathrm{~km}$ thick; thus, $\mathrm{P}$ to $\mathrm{S}$ converted phases ( $\mathrm{Pds}$ ) should be studied at frequencies higher than $0.1 \mathrm{~Hz}$. However, in this particular frequency range, the microseismic coherent noise has maximum energy. Numerous global studies of the $660 \mathrm{~km}$ interface have been conducted at frequencies lower than $0.17 \mathrm{~Hz}$ in order to remove this noise (see [Chevrot et al., 1999] for a review), but they exhibit a radial resolution worse than $30 \mathrm{~km}$. In this paper, we apply the wavelet transform to high frequency (0.1-1Hz) deconvolved Pds Very Broad Band (VBB) waveforms. This data processing technique, which has been used in various geophysical fields (e.g., [Paulssen, 1985; Kumar et al., 1997; Moreau et al., 1999; Valéro, 2000]), makes it possible for us: (1) to detect accurately the arrival time of seismic phases converted at sharp (less than $10 \mathrm{~km}$ thick) discontinuities (2) to highlight waveforms generated through high seismic gradients and derive their frequency content, and consequently (3) to improve the radial resolution of seismic models close to the $660 \mathrm{~km}$ depth range. The efficiency of the method is discussed using VBB data recorded at 3 FDSN California stations.

\section{Data processing}

We convolve the discrete complex Morlet wavelet (e.g. Morlet et al., [1982]) with the studied signal, in the frequency range 0.1 to $1 \mathrm{~Hz}$ to obtain its energy and phase diagram. Thus we can expect a radial resolution bounded by 6 and $60 \mathrm{~km}$, roughly. Exploiting different values of the non-dimensional gaussian width of the wavelet $\sigma$ illuminates complementary information: high values $(\sigma>1)$ provide a better resolution in the frequency domain while smaller values favor the accurate detection of arrival times. An initial data set of 138 three-component seismograms generated between 1991 and 1996 in the Tonga subduction zone - in the magnitude range of 5.5 to 7 , and depth ranges of $0-70 \mathrm{~km}$ and $400-680 \mathrm{~km}$ - has been constructed with epicentral distances contained between 65 and $85 \mathrm{deg}$. for the 3 stations under study (figure 1a). Only events displaying a signal to noise $(\mathrm{S} / \mathrm{N})$ ratio greater than 10 for the $\mathrm{P}$-wave arrival on the longitudinal component are of interest. Biases introduced by azimuthal anisotropy [Montagner, 1998] are reduced by restricting the backazimuthal aperture to \pm 10 degrees. The latter constraints define a final data set of 52 three compo- 


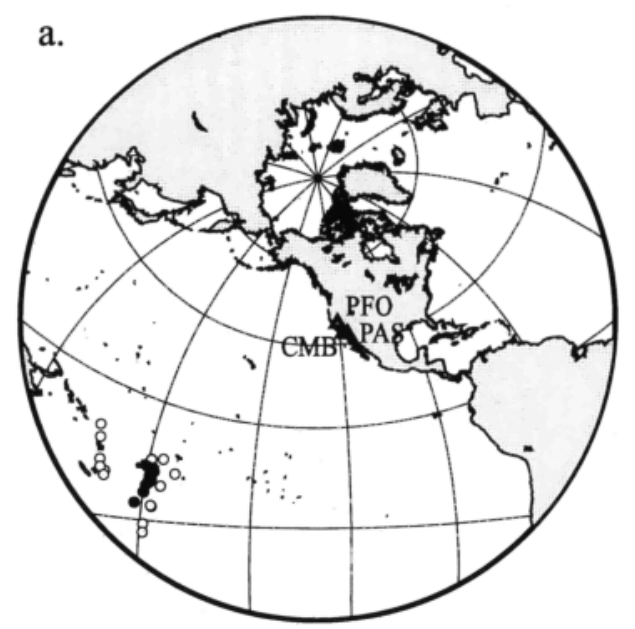

b.

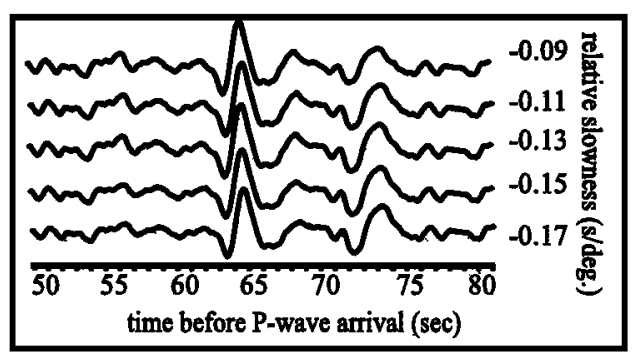

Figure 1. (a) Stations (triangles) and events used in this study. Black circles : deep events (hypocenter depth greater than $450 \mathrm{~km}$ ) ; white circles : shallow events (hypocenter depth smaller than $70 \mathrm{~km}$ ). (b) Stacked receiver functions as a function of slowness. Slowness values are relative to the one of the direct $P$-wave.

nent traces. Two subsets are constructed in order to detect possible artifacts induced by heterogeneities in the source region, and to test the redundancy of the interpretation in terms of mantle structure. The subsets consist of 34 shallow events (focal depth $\mathrm{h}$ shallower than $70 \mathrm{~km}$ ), and 18 deep events $(h \geq 400 \mathrm{~km})$, respectively. The stacked receiver functions are obtained using Vinnik's [1977] method for a reference distance of $75 \mathrm{deg}$. The time window of the deconvolving $\mathrm{P}$-wave is tested in the range 10 to $40 \mathrm{~s}$. The slowness values of the normal move-out corrections are tested in the

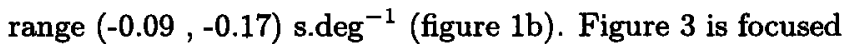
on $\mathrm{P}$ to $\mathrm{S}$ conversions at $660 \mathrm{~km}$ depth. Between 53 and $75 \mathrm{sec}$, the maximum error on arrival times is lower than $\pm 0.3 \mathrm{sec}$. The energy level of the post-stack noise sampled before the P-wave arrival is illustrated in figure 2 . In the frequency range $0.1-1.0 \mathrm{~Hz}$, the noise energy level is dominated by the coherent microseismic noise at $0.25 \mathrm{~Hz}$ (figure 2a). Deconvolution and stacking serve to increase the $S / N$ ratio and spread out the noise level distribution over all the frequency range (figure $2 \mathrm{~b}$ ). The $\mathrm{S} / \mathrm{N}$ ratio is close to 2.5 for the stack of the $52 \mathrm{SV}$-components, while it is lower than 0.5 for individual traces. This effect is important for further signal interpretation, since $0.2-0.4 \mathrm{~Hz}$ is the frequency range in which waves generated on upper mantle seismic gradients are expected to reach maximum energy.

\section{Results}

The stacked deconvolved Pds traces are shown in figures $3 a$ and $3 b$, respectively for deep and shallow events. Several packets stand out of the time frequency energy diagram. The features common to both stacks are described first. The energy maximum arrives with a time lag of \pm 3 s with respect to the $P 660$ s arrival time predicted by ak135. Two additional maxima are observed between 0.3 and $0.5 \mathrm{~Hz}$. The arrival times of the latter are around $66 \mathrm{~s}$, and $73 \mathrm{~s}$, respectively. Among the three successive arrivals, only the second one displays a significant dispersion over a $4 \mathrm{~s}$ wide time window, indicating a $20 \mathrm{~km}$ thick structure. The first and third phases are sharp and non-dispersive. This suggests that they were generated on discontinuities. On the shallow events stack (figure $3 a$ ) these arrivals dominate the track. The value of the first arriving energy is 3.5 times higher than the background energy level at $0.5 \mathrm{~Hz}$. Energies are twice higher than this level for the both last arrivals at $0.35 \mathrm{~Hz}$ and $0.4 \mathrm{~Hz}$, respectively. On the deep events stack (figure $3 \mathrm{~b}$ ), a fourth high energy arrival is observed around $57 \mathrm{~s}$. It is slightly dispersed over a $3 \mathrm{~s}$ wide window, and its frequency content is maximal around $0.3 \mathrm{~Hz}$, similar to the arrival around 65s. If we consider that the remainder of the seismogram corresponds to noise, the energy ratio of the four arrivals with respect to the maximal noise level is equal to 1.6 at $0.3 \mathrm{~Hz}, 1.6$ at $0.55 \mathrm{~Hz}, 2$ at $0.33 \mathrm{~Hz}$, and 1.2

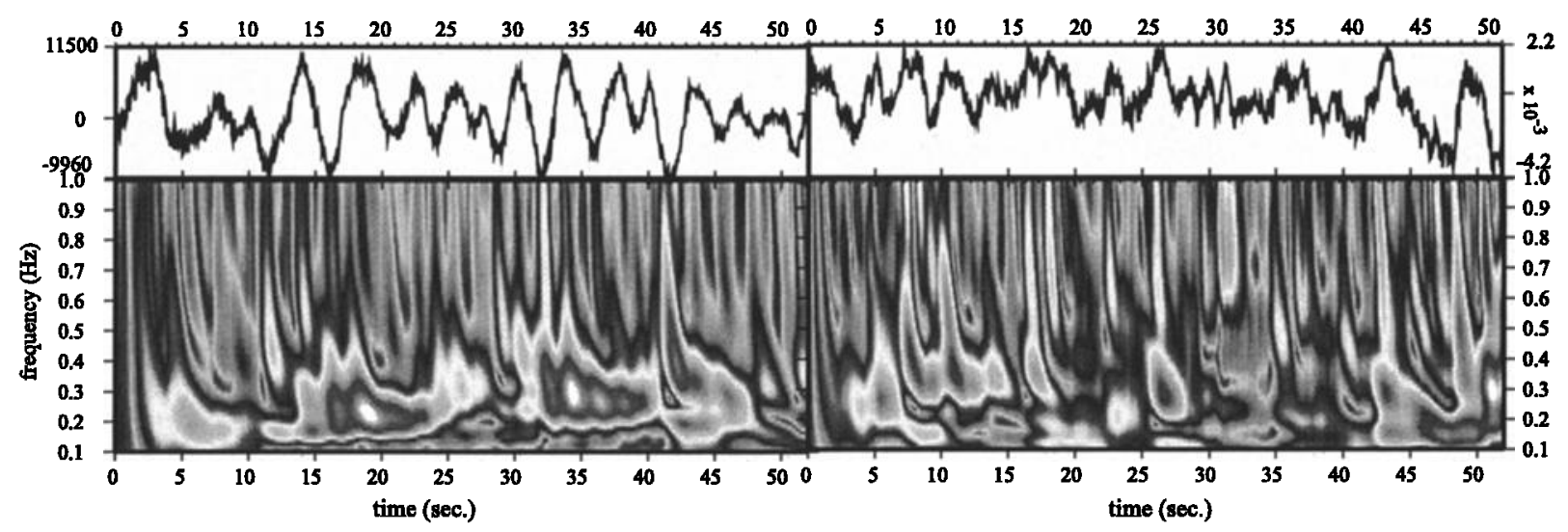

Figure 2. Effect of deconvolution on random and coherent noise. Energy diagrams of stack of seismograms recorded on the 52 invidual SV components before P-wave arrival (a) before and (b) after deconvolution. The corresponding energy scale bar is displayed in figure $3 c$. 

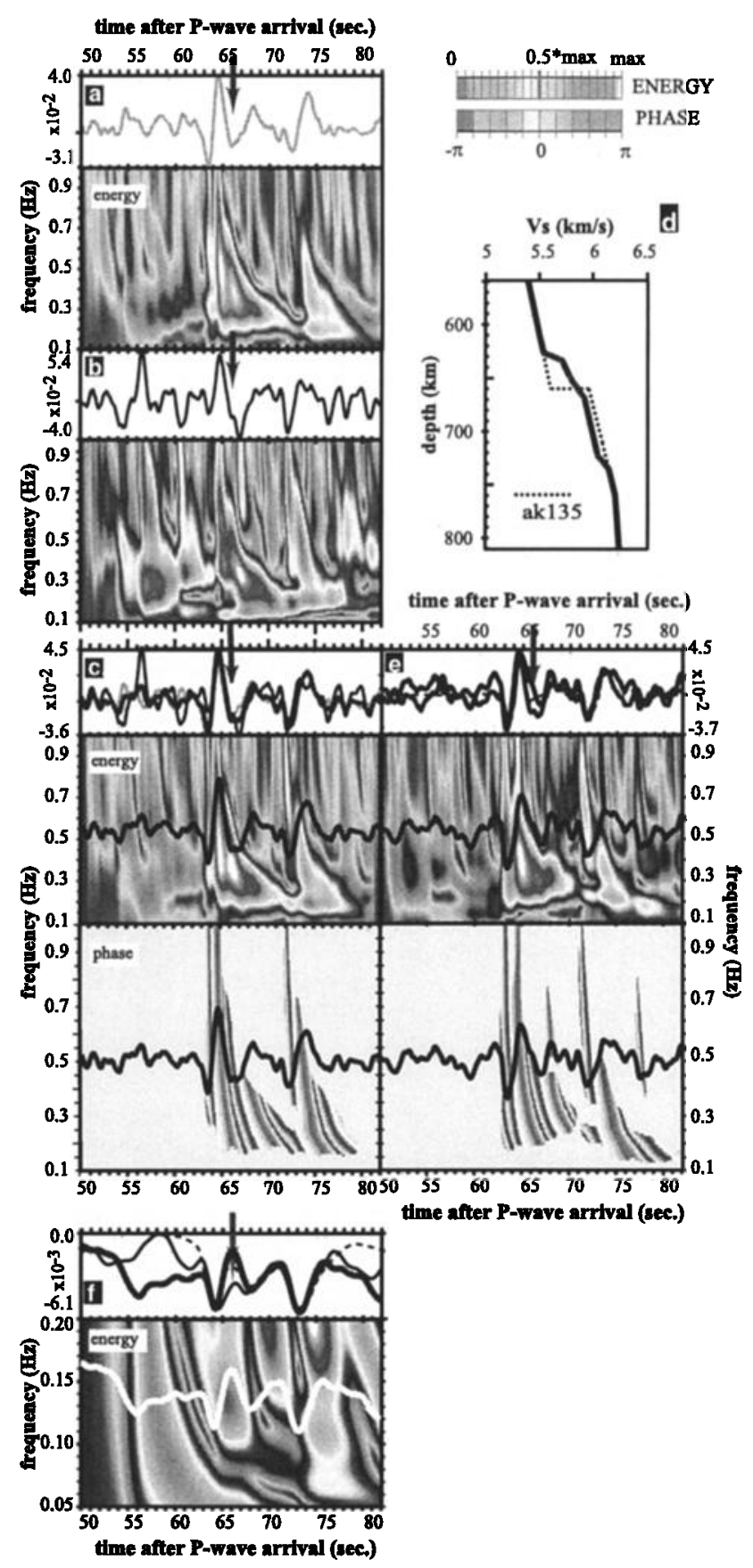

Figure 3. Wavelet transform of Californian Pds VBB records. Arrows point at the $\mathrm{P} 660$ s phase predicted by ak135. For sake of clarity, phases are displayed only if the energy is greater than one third of the maximum energy. Amplitudes are normalized with respect to the amplitude of the P-wave. (a) 34 shallow events stack; (b) 18 deep events stack; (c) total stack (heavy solid curve). (d) Shear wave velocity profile accounting the best for the observations. (e) thin curves correspond to synthetic seismograms without (dashed curve) and with (solid curve) noise, the heavy solid curve corresponds to the total stack of figure (c); the phase and energy diagrams correspond to the synthetic seismogram. (f) total stack (heavy solid line) and noisy synthetic seismogram (thin line) filtered with a 0.167 lowpass; the phase and energy diagrams belong to the total stack. A colored version of this figure is available on the website: http://www.sciences.univnantes.fr/geol/UMR6112/Persnl/JCastillo/castillo.html at $0.6 \mathrm{~Hz}$. These values confirm that the deep events stack is noisier than the shallow events one. Interference between noise and converted waveforms could be responsible for the differences in energy ratios between the different phases observed on each stack. The low energy ratios of the deep events stack make it difficult to discriminate between two interpretations : either the $57 \mathrm{~s}$, and the $66 \mathrm{~s}$ arrivals correspond to converted phases on mantle interfaces, or the energy diagram is dominated by noise. Similarities in both stacks (figures $3 \mathrm{a}$ and $3 \mathrm{~b}$ ) lead one to believe that the $66 \mathrm{~s}$ arrival is actually a converted phase on a $645 \mathrm{~km}$ depth interface, whereas the $57 \mathrm{~s}$ energy packet may only be associated with noise or attributed to structural complexities in the seismic source region. Figure 3c corresponds to the weighted sum of both stacks with a ratio $3: 2$, in order to take into account the difference of quality between both data sets. The use of the time-frequency phase diagram allows the precise recovery of the arrival time of the selected waveforms. It gives respective values of $63 \mathrm{~s}, 65.2 \mathrm{~s}$, and $72 \mathrm{~s}$. A search for the best fit between the observations and WKBJ seismograms [Chapman, 1978] in the frequency interval $0.1-1 \mathrm{~Hz}$ is conducted with the following unknown parameters : density, seismic velocities, and interface characteristics. The number of interfaces, as well as the initial values of their depth and thickness, are provided by the previous wavelet analysis. The ak135 parameters are left unchanged outside the investigated depth domain. Inside this domain, the total jump of parameters is distributed between the different interfaces, similarly for density and seismic velocities. Between the interfaces, ak135 velocity and density gradients remain unchanged. In the best $V_{S}$ profile, shown in figure $3 d$, the 3 interfaces located at 625,650 and $720 \mathrm{~km}$ depth are 10,18 and $13 \mathrm{~km}$ thick, respectively. The corresponding synthetic seismogram is displayed in figure 3e. The latter has been summed with a $32 \mathrm{~s}$ long noise series issued from figure $2 \mathrm{~b}$ with a $\mathrm{S} / \mathrm{N}$ ratio of 2 , and filtered in the frequency range $0.1-1 \mathrm{~Hz}$. Several stacks have been produced by delaying the noise track with respect to the bare synthetic seismogram. Though we have chosen the combination that fits the best with the observations, the interference between converted phases and noise results in slightly shifting their frequency content. This effect contributes to the error on the values of interfaces' depths and thickness by the order of $\pm 1 \mathrm{~km}$.

\section{Discussion}

Dispersed waveforms generated on seismic gradients become dominant at long period, and they may hide the presence of sharp discontinuities, especially if both structures are in close proximity to one another. In fact, geodynamical interpretation based on low frequency signals, and on the assumption of a single discontinuity at the base of the upper mantle can be biased by the inadequacy between signal wavelength and investigated structure thickness. A $0.167 \mathrm{~Hz}$ low-passed version of the total stack and its synthetics (figure 3f) shows that the three phases previously identified at higher frequencies (figure 3c) are more difficult- to discriminate. When interpreted at low frequencies, this observation leads to a two-layered structure of the investigated region. Figure $3 f$ also shows that low-pass filtering does not ensure a complete removal of the corrupting effect of microseismic noise. Care should thus be taken when interpreting seismic signals with wavelengths longer than the width of the sam- 
pled interfaces. A combined use of standard deconvolution techniques and the wavelet transform allows the seismic signal to stand out from noise, and individualize arrival times of sharp phases generated on seismic discontinuities from dispersed waveforms created by gradients. The high frequency $(0.1-1 \mathrm{~Hz})$ results obtained in the present study yield the relative depth and thickness of these structures with a better accuracy than lowpassed waveforms. Under California, we find a seismic structure which is more complex than usually observed by studies based on long-period data (e.g. Shearer and Flanagan [1999]. Our results are consistent with the larger scale observations of Simmons and Gurrola [2000] in the same region, i.e. the three interfaces located at 625,650 , and $720 \mathrm{~km}$ depth, respectively. Our model can be viewed as a lateral average of their detailed three dimensional map of the transition zone beneath California. The main difference between both studies lies in the visibility of the $625 \mathrm{~km}$ discontinuity, which is enhanced in our model while it is not present everywhere on a regional scale. We suspect the link between seismic interfaces and mineralogical transformations, as predicted in the laboratory, is not straightforward. For example, we obtain a thickness of about $20 \mathrm{~km}$ for the $650 \mathrm{~km}$ interface, while experimental studies [Ito and Takahashi., 1989] predict that the transformation of ringwoodite occurs over a region less than $5 \mathrm{~km}$ thick. The $625 \mathrm{~km}$ discontinuity may also be a good candidate for this reaction since Irifune et al. [1998] have reported that it could take place at mantle pressures valid at a depth of $600 \mathrm{~km}$. On the other hand the $720 \mathrm{~km}$ deep structure can be attributed more confidently to the transformation of ilmenite into perovskite, if one considers the depth range in which this transformation is likely to occur (e.g. Vacher et al. [1998]). The method which has been applied here proves itself to be a useful method for further observations in different geodynamical contexts and comparison with laboratory results.

Acknowledgments. This work was financed by French MRT, and by IT program of INSU. We acknowledge the IRIS team for providing the data and Scherbaum and Johnson for the PITSA toolkit. Figures have been designed with the GMT toolkit of Wessel and Smith, [1991]. Constructive comments by Pierre Vacher, Scott Turner and an anonymous reviewer have been helpful to improve a first version of this paper.

\section{References}

Chapman, C.H., A new method for computing synthetic seismograms, Geophys. J. R. astr. Soc., 54, 481-518, 1978.

Chevrot, S., Vinnik, L., and J.-P. Montagner, Global patterns of upper mantle from Ps converted waves, J. Geophys. Res., 104, 20203-20219, 1999.
Irifune, T. N. Nishiyama, K. Kuroda, T. Inoue, M. Isshiki, W. Utsumi, K. Funakoshi, S. Urakawa, T. Uchida, T. Katsura, and $\mathrm{O}$. Ohtaka, The postspinel phase boundary in $\mathrm{Mg}_{2} \mathrm{SiO}_{4}$ determined by in-situ X-ray diffraction, Science, 279, 1698$1700,1998$.

Ito, E., and E.Takahashi., Postspinel transformations in the system $\mathrm{Mg}_{2} \mathrm{SiO}_{4}-\mathrm{Fe}_{2} \mathrm{SiO}_{4}$ and some geophysical implications, $J$. Geophys. Res., 94, 10,637-610,646, 1989.

Kennett, B.L.N., E.R. Engdahl, and R. Buland, Constraints on seismic velocities in the Earth from traveltimes, Geophy. J. Int., 122, 108-124, 1995.

Kumar, $\mathrm{P}_{\text {., }}$ and E. Foufoula-Georgiou, Wavelet analysis of geophysical applications, Rev. Geophys., 35, 385-412, 1997.

Montagner J.-P., Where can Seismic Anisotropy be detected in the Earth's Mantle? In Boundary Layers..., Pageoph., 151, $223-256,1998$.

Moreau, F., D. Gibert, M. Holschneider, and G Saracco, Identifcation of sources of potential fields with the continuous wavelet transform : 1 - Basic theory, J. Geophys. Res., 104, 5003-5013, 1999.

Morlet J., G. Arens, E. Fourgeau, and D. Girard, Wave propagation and sampling theory, Parts 1 an 2, Geophysics 47, 203-236, 1982.

Niu, F., and H. Kawakatsu, Complex structure of the mantle discontinuities at the tip of the subducting slab beneath the Northeast China : a preliminary investigation of broadband receiver functions, J. Phys. Earth, 44, 701-711, 1996.

Paulssen, H., Upper mantle converted waves beneath the NARS array, Geophys. Res. Lett., 12, 709-712, 1985.

Shearer, P.M., and M.P. Flanagan, Seismic velocity and density jumps across the 410- and 660-kilometer discontinuities, Science, 285, 1545-1548, 1999.

Simmons, N.A., and H. Gurrola, Multiple seismic discontinuities near the base of the transition zone in the Earth's mantle, Nature, 405, 559-562, 2000.

Vacher, P., A. Mocquet, and C. Sotin, Computation of seismic profiles from mineral physics : the importance of the nonolivine components for explaining the $660 \mathrm{~km}$ depth discontinuity, Phys. Earth Planet. Inter., 106, 275-298, 1998.

Valéro, H.-P., Endoscopie sismique, PhD thesis, 256 pp., Institut de Physique du Globe at Paris France, 2000.

Vinnik, L.P., Detection of waves converted from $P$ to $S V$ in the mantle, Phys. Earth Planet. Inter., 15, 39-45, 1977.

J. Castillo and A. Mocquet, Laboratoire de Planétologie et Géodynamique, UMR-CNRS 6112, Faculté des Sciences et Techniques, 2, rue de la Houssiniere, 44300 Nantes, FRANCE (e-mail: castillo@chimie.univ-nantes.fr)

G. Saracco, Laboratoire de Géosciences Rennes, UPR 4661, Campus de Beaulieu, 263 av. du Général Leclerc, 35042 Rennes, FRANCE

(Received March 22, 2001; revised August 04, 2001; accepted September 05, 2001.) 